\title{
The resting sites and blood-meal sources of Anopheles minimus in
}

\section{Taiwan}

\author{
Mei-Chun Chang1, Hwa-Jen Teng*1, Chen-Fu Chen ${ }^{1}$, Yung-Chen Chen ${ }^{1}$ and \\ Chian-Ren Jeng ${ }^{2}$
}

\author{
Address: ${ }^{1}$ Research and Diagnostic Center, Centers for Disease Control, Taiwan and ${ }^{2}$ Department of Veterinary Medicine, National Taiwan \\ University, Taipei, Taiwan \\ Email: Mei-Chun Chang - newlover@cdc.gov.tw; Hwa-Jen Teng* - hjteng@cdc.gov.tw; Chen-Fu Chen - afuchen@cdc.gov.tw; Yung- \\ Chen Chen - r88632006@msa.ntu.edu.tw; Chian-Ren Jeng - crjeng@ntu.edu.tw \\ * Corresponding author
}

Published: 9 June 2008

Malaria Journal 2008, 7:105 doi:10.1186/1475-2875-7-105
Received: 27 February 2008

Accepted: 9 June 2008

This article is available from: http://www.malariajournal.com/content/7/I// 05

(C) 2008 Chang et al; licensee BioMed Central Ltd.

This is an Open Access article distributed under the terms of the Creative Commons Attribution License (http://creativecommons.org/licenses/by/2.0), which permits unrestricted use, distribution, and reproduction in any medium, provided the original work is properly cited.

\begin{abstract}
Background: The WHO declared Taiwan free from malaria in 1965, but in 2003 the reporting of two introduced cases in a rural area suggested a possible local transmission of this disease. Therefore, understanding the resting sites and the blood sources of Anopheles minimus is crucial in order to provide information for implementing vector control strategies.
\end{abstract}

Methods: During a two-year survey, mosquitoes were collected in houses and their surrounding areas and at the bank of larval habitats by backpack aspirators in 17 villages in rural areas of southern and eastern Taiwan for I hr. On the same day, blacklight traps were hung downward overnight. Blood-fed mosquito samples were analysed by PCR.

Results: Of the 195 total households surveyed by backpack aspirators, no Anopheles adults were collected inside the houses, while a single Anopheles minimus and a single Anopheles maculatus were collected outside of the houses. On the same day, 23 An. minimus, two An. maculatus, two Anopheles ludlowae, two Anopheles sinensis, and one Anopheles tessellatus were collected along the bank of larval habitats. In blacklight traps hung outside of the houses in the villages, $69 \mathrm{An}$. minimus, $62 \mathrm{An}$. ludlowae, 3I An. sinensis, and 19 An. maculatus were collected. In larval habitats, 98 An. ludlowae, 64 An. minimus, 49 An. sinensis, and 14 An. maculatus were collected. Of a total of 10 blood-fed samples, An. minimus fed on four animals including bovine $(60 \%)$, dogs (20\%), pig (10\%), and non-chicken avian (10\%).

Conclusion: Anopheles minimus, an opportunist feeder in Taiwan, was not collected inside the houses, but was found outside of the houses in villages and surrounding larval habitats. Therefore, an outdoor transmission of malaria is likely to occur and, thus, the bed nets, which are favoured for controlling the late biting of An. minimus, should be a very efficient and effective method for those local residents who sleep outdoors. Additionally, space spray of insecticides for Anopheles at night, as well as residual spray inside animal huts and selective larval habitats, are also helpful to control female adults. 


\section{Background}

Malaria is documented to have been prevalent throughout much of Taiwan in the $19^{\text {th }}$ and $20^{\text {th }}$ centuries. The maximum estimated case number was 1.2 million in 1952 [1]. In November 1946, the International Health Division of the Rockefeller Foundation, in collaboration with the Taiwanese government, established a Malaria Research Center in southern Taiwan in order to instigate a series of antimalaria measures. Among these actions, a four-year island-wide malaria control programme was launched in 1951. The principal control measure was indoor residual house spraying with DDT (0.5-2.0 g of active ingredient per $\mathrm{m}^{2}$ ), which was conducted in conjunction with the larviciding of streams with DDT and automatic flushing of streams. As a result of the success of these actions and patient treatments, the World Health Organization (WHO) declared Taiwan to be free from malaria on December 4, 1965. Furthermore, after 1973, almost all of the reported cases of malaria in Taiwan (22-83 cases per year) were imported [1-3].

Among the 15 Anopheline species that are found in Taiwan, Anopheles minimus is regarded as the principal malaria vector [4]. This species (A) is the malaria vector in the Oriental Region and its morphology is similar to its two sibling species, $C$ and $E[5,6]$. Recently, species $C$ was resolved as Anopheles harrisoni by comparing DNA sequence data [7]. Based on DNA analysis of the D3 region of the $28 \mathrm{~S}$ gene of ribosomal DNA, samples collected from Taiwan are identical to species A $[8,9]$. Species A has now formally been recognized as An. minimus s.s. [10]. More thorough study on molecular identification of An. minimus is on going to include samples collected from wider areas. Anopheles minimus is able to change its host preference based on host availability and is known as an opportunist feeder $[11,12]$. The vector status of the secondary species, Anopheles sinensis, was questioned by the misidentification of one slide from a 1947-1949 study [4], on which the crithidial flagellates had been misidentified as malaria sporozoites. Of the other 14 Anopheline species in Taiwan, Anopheles maculatus, Anopheles ludlowae, Anopheles tessellatus, Anopheles jeyporiensis and Anopheles annularis have been implicated in malaria transmission in other countries; however, they are not considered to be potential vectors of malaria in Taiwan [4].

In addition to the imported malaria found in Taiwan, induced malaria also occurred in 1980 (1 case), 1995 (6 cases with 66.67\% mortality), and 1997 ( 1 case) [2]. In August 2003, two cases of locally transmitted malaria (the first since the eradication of malaria in Taiwan) occurred in a rural area of Taitung County. However, only the presence of an imported Plasmodium carrier, the existence of competent female vectors (An. minimus), and the highrisk behaviour of sleeping outdoors suggest the possibility of mosquito transmission. Since the eradication of malaria in Taiwan, environmental and housing conditions have largely changed. Data on the resting sites and blood-fed hosts of the malaria vectors need to be updated in order to provide information for implementing vector control strategies. The objective of this study is to understand the resting sites and blood-meal sources of An. minimus in Taiwan.

\section{Methods \\ Resting site study and mosquito collection}

The survey villages (in southern and eastern Taiwan) were chosen based on a large number of An. minimus adults collected by light traps during the same year or the previous year (Figure 1). Based on the surveys conducted by local health bureaus, the average density ( \pm SD) of An. minimus at the study villages comparing with that of all villages examined were $1.80 /$ night/trap $( \pm 8.56)$ in the study villages and $0.32 /$ night/trap $( \pm 3.18)$ in all villages examined. From April to September in 2005 and 2006, two to three villages were surveyed each month. On each visit, a larval survey by 14 -cm-diameter dippers was conducted along the bank of streams and ditches around or in the surveyed village. A section of a larval habitat was chosen in the morning based on the collection of An. minimus larvae or, at least, other Anopheles larvae. Two teams collected mosquito adults along the bank and its surroundings for $1 \mathrm{hr}$ during the period between 10:00 and 12:00. Each team included two individuals with one modified CDC backpack aspirator (Model 1412, John W. Hock Company, Gainesville, Florida) and one sweeping net. During the period between 15:00 and 17:00, the same $1 \mathrm{hr}$ collection was also conducted in human dwellings, including inside the houses and their surroundings. The mean number $( \pm$ SD) of houses sampled per visit was $9.75( \pm$ 1.77). Screen conditions for each surveyed house were recorded. On the same day, one updraft blacklight (UV) trap (Model 1312, John W. Hock Company, Gainesville, Florida) with dry ice was set up downward outside of the houses and the larval habitat, (separately) overnight. All collected mosquitoes were stored in a dry ice box and brought back to the laboratory for species identification. Blood-fed mosquitoes were kept at $-20^{\circ} \mathrm{C}$ for blood meal identification. Additional mosquitoes were collected in animal huts (including pigs, buffalos, and horses) by aspirators or blacklight traps outside of the villages in order to increase the blood-fed mosquito sample.

\section{Blood-meal identification}

Blood-fed mosquitoes were processed individually using the PCR method to identify the blood-meal source. Genomic DNA from blood-fed mosquitoes was extracted using the QIAamp DNA Mini Kit (Qiagen GmbH, Hilden, Germany) and the protocol described by the manufacturer was followed. The same DNA extraction procedure 


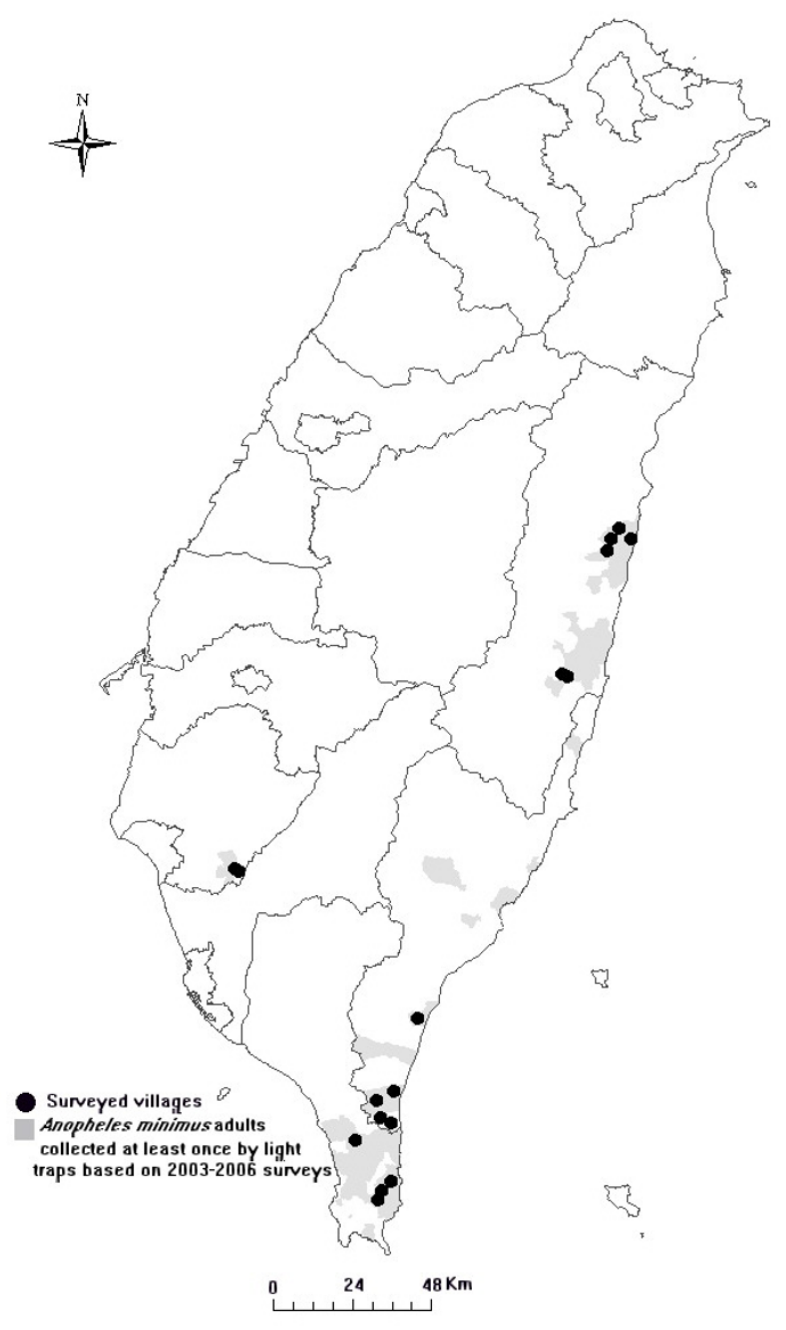

\section{Figure I}

The survey villages and distribution map of Anopheles minimus. Dark solid circles indicate the survey villages in rural areas in southern and eastern Taiwan and the gray areas indicate the collection of Anopheles minimus adults (at least once) based on the light trap data from 2003 to 2006 in Taiwan.

was also applied to blood samples of 10 common animals (i.e., bovine, cat, chicken, dog, goat, horse, human, monkey, pig, and rat) in Taiwan to serve as positive controls and clarify the cross reactions of animal blood. Non-fed mosquitoes served as negative controls. The sensitivity of this test was demonstrated in detection of blood-fed Aedes aegypti in a laboratory colony up to five days ( $1 \mathrm{hr}, 1$ day, 2 days, 3 days, 4 days, and 5 days) after blood-feeding on a mouse.

The PCR amplifications were conducted in $50 \mu \mathrm{l}$ of a solution containing $10 \mathrm{mM}$ Tris-HCL (pH 8.3), $50 \mathrm{mM} \mathrm{KCL}$,
$1.5 \mathrm{mM} \mathrm{MgCl} 2,2.5 \mathrm{mM}$ dNTP Mix, $1 \mu \mathrm{M}$ of each primer, 5 units/ $\mu$ l of Tag DNA polymerase (TAKARA BIO Inc., Shiga, Japan), and $1 \mu$ l of DNA product. The sequences of the primers for the 10 animals used in the PCR are listed in Table 1. Two additional order-specific primers (mammalian and avian) were included to detect other possible hosts as well. Reactions began with an incubation at $94^{\circ} \mathrm{C}$ for $2 \mathrm{~min}$, followed by 35 cycles consisting of $94^{\circ} \mathrm{C}$ at 30 sec, $54-70^{\circ} \mathrm{C}$ at $30 \mathrm{sec}$ (detailed temperature for each primer listed in Table 1 ), and $72^{\circ} \mathrm{C}$ at $30 \mathrm{sec}$. The reaction was completed by incubation at $72^{\circ} \mathrm{C}$ for $20 \mathrm{~min}$ and kept at $4{ }^{\circ} \mathrm{C}$. Then, $17 \mu \mathrm{l}$ samples of PCR products were analyzed using a $2 \%$ agarose gel in Tris Borate EDTA and visualized on a UV light box after ethidium bromide staining. Negative and positive controls were included in each PCR.

\section{Statistical analysis}

Data were transformed by square root of $(\mathrm{x}+0.5)$ prior to analysis to meet the assumptions of t-test [13]. Because of the dependence of the data at the same collection site, paired $t$ tests were used to compare differences among the number of Anopheles mosquitoes collected at different collection sites under different collection methods. Furthermore, the number of Anopheles mosquitoes collected against the number of Armigeres, Aedes, and Culex under different collection sites and methods were also compared by this test.

\section{Results}

\section{Resting site study}

After a two-year survey in 17 villages (20 visits), with a total of 195 households surveyed, significantly more Anopheles mosquitoes were collected by blacklight traps than by backpack aspirators in human dwellings $\left(t_{19}=\right.$ 3.59, $P<0.01)$ but not in larval habitats $\left(t_{19}=2.00, P>\right.$ $0.05)$. No differences were found in locations by the same collecting methods $\left(t_{19}=0.11\right.$ and $\left.1.61, P>0.05\right)$. No Anopheles adults were collected inside the houses while a single An. minimus and a single An. maculatus were collected outside of the houses (Table 2). At the same time, 23 An. minimus, two An. maculatus, two An. ludlowae, two An. sinensis, and one An. tessellatus were collected along the bank of larval habitats. Most of the Anopheles adults (27 out of 30) were collected in one location over two years (Figure 2). In 2005, An. minimus (five females), An. tessellatus (one female), An. sinensis (two males), Culex quinquefasciatus (six females and two males), Culex tritaeniorhynchus (five females and four males), Culex annulus (two females), Culex fuscocephala (one female), Armigeres subalbatus (one female and two males), and Aedes albopictus (one male) were collected at the same time and the dominant plant was a native fern (Asplenium antiquum). In 2006, An. minimus (12 females and five males), An. ludlowae (two females), Cx. annulus (12 females and one 
Table I: Order-specific group primers and species-specific primers used in blood-meal identification

\begin{tabular}{|c|c|c|c|}
\hline Test animal & Primer sequence' (F: forward 5'-3' and R: reverse 5'-3') & Annealing temp $\left({ }^{\circ} \mathrm{C}\right)$ & Size of amplified products (bp) \\
\hline Avian & $\begin{array}{l}\text { F: GACTGTGACAAAATCCCNTTCCA } \\
\text { R: GGTCTTCATCTYHGGYTTACAAGAC }\end{array}$ & 64 & 508 \\
\hline Mammalian & $\begin{array}{l}\text { F: CGAAGCTTGATATGAAAAACCATCGTTG } \\
\text { R: TGTAGTTRTCWGGGTCHCCTA }\end{array}$ & 59 & 772 \\
\hline Chicken & $\begin{array}{l}\text { F: GGGACACCCTCCCCCTTAATGACA } \\
\text { R: GGAGGGCTGGAAGAAGGAGTG }\end{array}$ & 69 & 266 \\
\hline Bovine & $\begin{array}{l}\text { F: GCCATATACTCTCCTTGGTGACA } \\
\text { R: GTAGGCTTGGGAATAGTACGA }\end{array}$ & 61 & 271 \\
\hline Pig & $\begin{array}{l}\text { F: GCCTAAATCTCCCCTCAATGGTA } \\
\text { R: ATGAAAGAGGCAAATAGATTTTCG }\end{array}$ & 64 & 212 \\
\hline Goat & $\begin{array}{l}\text { F: TTAAAGACTGAGAGCATGATA } \\
\text { R: ATGAAAGAGGCAAATAGATTTTCG }\end{array}$ & 54 & 225 \\
\hline Cat & $\begin{array}{l}\text { F: TTCTCAGGATATACCCTTGACA } \\
\text { R: GAAAGAGCCCATTGAGGAAATC }\end{array}$ & 60 & 180 \\
\hline Dog & $\begin{array}{l}\text { F: GAACTAGGTCAGCCCGGTACTT } \\
\text { R: CGGAGCACCAATTATTAACGGC }\end{array}$ & 67 & 153 \\
\hline Horse & $\begin{array}{l}\text { F: CCCTAAGCCTCCTAATCCGT } \\
\text { R: AGGAATGATGGGGGAAGTAA }\end{array}$ & 56 & 235 \\
\hline Human & $\begin{array}{l}\text { F: TTCGGCGCATGAGCTGGAGTCC R: } \\
\text { TATGCGGGGAAACGCCATATCG }\end{array}$ & 70 & 228 \\
\hline Monkey & $\begin{array}{l}\text { F: CCTCTTTCCTGCTGCTAATG } \\
\text { R: TTTGATACTGGGATATGGCG }\end{array}$ & 62 & 222 \\
\hline Rat & $\begin{array}{l}\text { F: CGGCCACCCAGAAGTGTACATC R: } \\
\text { GGCTCGGGTGTCTACATCTAGG }\end{array}$ & 67 & 196 \\
\hline
\end{tabular}

IThe primer sequences were cited from papers of Ngo and Kramer [22], Lahiff et al [23] and Parodi et al [24].

male), Cx. tritaeniorhynchus (seven females), and Ae. albopictus (three females) were collected and the dominant plant was a native Bidens pilosa. In light traps hung outside of the houses in human dwellings, 69 An. minimus, 62 An. ludlowae, 31 An. sinensis, and 19 An. maculatus were collected, while 98 An. ludlowae, 64 An. minimus, 49 An. sinensis, and 14 An. maculatus were collected in larval habitats.
Significantly more Armigeres $\left(t_{19}=3.09, P<0.01\right)$, Aedes $\left(t_{19}=2.88, P<0.01\right)$ and Culex $\left(t_{19}=2.37, P<0.05\right)$ adults were collected indoors by backpack aspirators than Anopheles mosquitoes. Similar results were found for backpack aspirators used outdoors (Armigeres vs. Anopheles $t_{19}=$ 4.78, $P<0.001$;Aedes vs. Anopheles $t_{19}=5.70, P<0.001$; Culex vs. Anopheles $\left.t_{19}=3.06, P<0.01\right)$. The dominant mosquito species collected outdoors in human dwellings

Table 2: Number of mosquitoes collected using different collection methods in 20 visits ( 17 villages of 4 counties) Taiwan, 2005-2006

\begin{tabular}{|c|c|c|c|c|c|c|c|}
\hline \multirow{3}{*}{ Mosquito species } & \multicolumn{4}{|c|}{ CDC backpack aspirators ${ }^{\prime}$} & \multicolumn{2}{|c|}{ Blacklight traps' } & \multirow{3}{*}{ Total } \\
\hline & \multicolumn{3}{|c|}{ Human dwelling } & \multirow[t]{2}{*}{ Larval habitat } & \multirow[t]{2}{*}{ Human dwelling (outdoor) } & \multirow[t]{2}{*}{ Larval habitat } & \\
\hline & Indoor ${ }^{2}$ & Outdoor & Total & & & & \\
\hline Anopheles species & 0 & 2 & 2 & 30 & $|8|$ & 225 & 438 \\
\hline An. minimus & 0 & I & 1 & 23 & 69 & 64 & 157 \\
\hline An. maculatus & 0 & I & 1 & 2 & 19 & 14 & 36 \\
\hline An. ludlowae & 0 & 0 & 0 & 2 & 62 & 98 & 162 \\
\hline An. sinensis & 0 & 0 & 0 & 2 & 31 & 49 & 82 \\
\hline An. tessellatus & 0 & 0 & 0 & I & 0 & 0 & 1 \\
\hline Culex species & 73 & 135 & 208 & 66 & 386 & 187 & 847 \\
\hline Aedes and Ochlerotatus species & 14 & 115 & 129 & 113 & 260 & 1,675 & 2,177 \\
\hline Armigeres species & 87 & 229 & 316 & 5 & 187 & 5 & 513 \\
\hline Other species & 0 & 0 & 0 & I & 8 & 2 & II \\
\hline Total & 174 & 481 & 655 & 215 & 1,022 & 2,094 & 3,986 \\
\hline
\end{tabular}

I In each visit, two backpack aspirators were used to collect inside and outside of the houses for I hr and a section of a larval habitat for I hr, respectively. On the same day, one blacklight trap hung downward overnight to collect adults outside of the houses and the bank of the larval habitats, respectively. ${ }^{2}$ The house number surveyed was 195. 


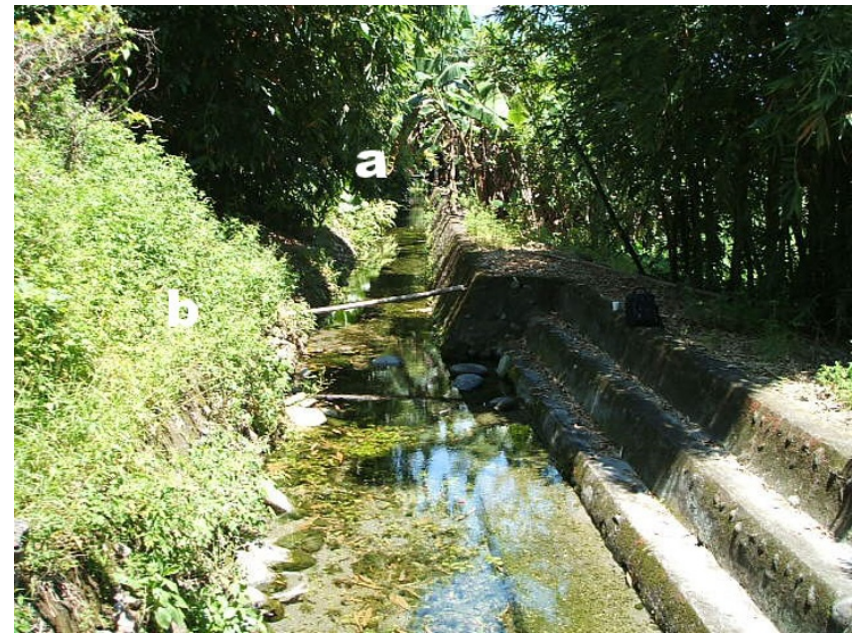

Figure 2

Typical resting sites of Anopheles minimus adults in a ditch in Hwalien County, Taiwan. a: the collection site of Anopheles minimus ( 5 females) in 2005 with a native fern (Asplenium antiquum Makino) and b: the collection site of An. minimus ( 12 females and five males) in 2006 with a native plant (Bidens pilosa L.).

by backpack aspirators were Ar. subalbatus (47.6\%), $C x$. quinquefasciatus (26.4\%), and Ae. albopictus (23.7\%). Five other mosquito species found in small numbers were $C x$. tritaeniorhynchus $(1.2 \%), C x$. annulus $(0.4 \%)$, An. minimus $(0.2 \%)$, An maculatus $(0.2 \%)$, and Aedes vexans vexans (0.2\%). Of the 174 mosquitoes collected indoors, only $A r$. subalbatus (50\%), Cx. quinquefasciatus (42\%), and $A e$. albopictus (8\%) were present. No difference of Aedes, Armigeres, and Culex against Anopheles adults $\left(t_{19}=0.03-\right.$ $1.85, P>0.05)$ was found for data in larval habitats collected by backpack aspirators or blacklight traps or in human dwellings collected by blacklight traps.

In addition, the screen conditions of each house surveyed in 2006 (a total of 85 houses) were checked. Half (52\%) of surveyed houses had completely screened doors and windows, $15 \%$ of the surveyed houses were partially screened, and $33 \%$ of the surveyed houses were not screened (Table 3).

\section{Blood-meal identification}

Figure 3 showed the results for the sensitivity of the PCR test in detection of blood-fed Ae. aegypti in a laboratory colony up to five days (Lane 3 to 8 ) after blood-feeding on a mouse. The expected 196 bp PCR product was detected in all the samples collected $1 \mathrm{hr}, 1$ day, 2 days, 3 days, 4 days, and 5 days after blood-feeding. Among 10 blood-fed An. minimus, six females $(60 \%)$ fed on bovine, two females $(20 \%)$ on dog, one female $(10 \%)$ on pig, and one female $(10 \%)$ for non-chicken avian (Table 4). Among 44 blood-fed An. sinensis, almost $86.4 \%$ of the females (38 females) fed on pig, followed by bovine (9.1\%) and horse $(4.5 \%)$. Three and one An. maculatus females fed on bovine and dog, respectively. Anopheles ludlowae fed on bovine (two females) and horse (one female). A single $A n$. tessellatus female fed on bovine. Human, dog, pig, bovine, horses, and non-chicken avian were detected in Culex or Aedes blood-fed samples.

\section{Discussion}

In this study, no Anopheles adults were collected inside the houses but two Anopheles adults and a large number of Anopheles (including An. minimus) were collected outside of the houses by backpack aspirators and blacklight traps, respectively. The principal malaria vector, An. minimus, fed on four animals, including bovine, dog, pig, and nonchicken avian. Therefore, an outdoor transmission of malaria is likely to occur.

No Anopheles adults were collected inside the houses while the surveyed houses were not fully screened $(15 \%$ partial screens plus 33\% no screens). Significantly more Ar. subalbatus and Ae. albopictus were collected inside the houses. These two species are dusk or day biters, making local residents close the door and windows at sunset or use repellents/insecticides to prevent mosquito bites. These behaviours of local residents gave late night species

Table 3: Window and door screens in the households of rural areas, Taiwan, 2006

\begin{tabular}{|c|c|c|c|c|c|c|c|c|}
\hline \multirow{3}{*}{ Location } & \multirow{3}{*}{ Village no. } & \multirow{3}{*}{ House no. } & \multicolumn{6}{|c|}{ Screens on window and door } \\
\hline & & & \multicolumn{2}{|l|}{ Complete } & \multicolumn{2}{|c|}{ Partial' } & \multicolumn{2}{|c|}{ No } \\
\hline & & & House & $\%$ & House & $\%$ & House & $\%$ \\
\hline Hwa-lien & 4 & 36 & 20 & $56 \%$ & 6 & $17 \%$ & 10 & $28 \%$ \\
\hline Tai-tung & 2 & 24 & 12 & $50 \%$ & 3 & $13 \%$ & 9 & $38 \%$ \\
\hline Ping-tung & 2 & 17 & 6 & $35 \%$ & 4 & $24 \%$ & 7 & $41 \%$ \\
\hline Tainan & I & 8 & 6 & $75 \%$ & 0 & $0 \%$ & 2 & $25 \%$ \\
\hline Total & 9 & 85 & 44 & $52 \%$ & 13 & $15 \%$ & 28 & $33 \%$ \\
\hline
\end{tabular}

'Partial indicate that at least one window or door was not closed in the survey (i.e., in the afternoon 15:00-17:00). 


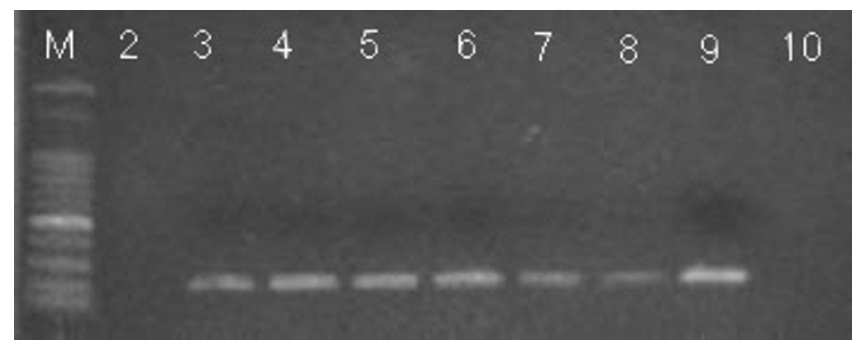

Figure 3

Analysis of bloodmeal on blood-fed Aedes aegypti females in a laboratory colony up to five days after blood-feeding on a mouse by PCR (196 bp product). Lane M, DNA molecular weight marker; lane 2 before fed; lane $3 \mathrm{I}$ hr after blood-fed; lane $4 \mathrm{I}$ day after blood-fed; lane 52 days after blood-fed; lane 63 days after blood-fed; lane 7 4 days after blood-fed; lane 85 days after blood-fed; lane 9 mouse blood; lane 10 negative control.

no chance to enter the houses and bite people. The biting rhythm of An. minimus was different by location as a result of the local condition. In Lang Nhot, Central Vietnam [12] and Taiwan [14], this species was a late night biter. Hence, in Taiwan, the behaviour of local residents prevented these mosquitoes from entering the house. Furthermore, this species will not rest on indoor surfaces after biting.

The indoor and outdoor biting activities of An. minimus are varied by location and surveyed time $[11,15]$. The surveys in Rattanakiry, Cambodia and Vientiane, Lao in 1999 showed that the biting density at outdoor collection was higher than indoor in hot season (March) while the opposite result was found in cool season (October) [15]. In this study, the survey was conducted only in one hot season (April to September). In order to conclude the low possibility of indoor malaria transmission in Taiwan, the same study in cool season should be conducted to clarify this point. Additionally, the sampling strategy of this study biased on outside collections, which only one $1 \mathrm{hr}$-indoor collection in late afternoon was made. This indoor collection in daytime referred to the resting population only. No information on the indoor biting activity of these mosquitoes at night was available in this study. There is a possibility that An. minimus females enter the house, blood feed on human, and exit from the house to the bank of the nearby breeding sites within one night. Further study should be conducted to clarify this point before any solid conclusion can be made on low possibility of indoor malaria transmission in Taiwan.

In this study, An. minimus fed on four animal's blood. Therefore, these results suggest that the local population of An. minimus is an opportunist feeder in Taiwan. All blood fed samples of An. minimus except one female (collected from a pig farm) were collected by backpack aspirators or blacklight traps. However, the host-feeding pattern described refers only to the relative frequency of blood source detection in the blood-meal samples, which does not necessarily imply a higher preference for a particular host. In Southeast Asia, An. minimus was either zoophilic or anthropophilic, depending on the local host availability $[11,12]$. The host preferences of An. minimus in Taiwan reported in 1933 [16] were bovine (68.5\%), human $(25.2 \%)$, chicken $(3.5 \%)$, and pig (2.8\%). In comparing the current results with those of 1933, both studies detected bovine and pig. No human and chicken but, instead, dog and non-chicken avian were detected. Because dogs live very close to their owners and An. minimus females were found outside of the houses in human dwellings, outdoor transmission is still possible, such as in the cases that occurred in 2003. The patients slept outdoors overnight.

Three malaria control measures directed towards adult mosquitoes were considered in malaria epidemic areas [17]. The first was indoor residual spraying, a treatment that can effectively control epidemics but only when

Table 4: Sources of origin for mosquito blood-meals determined by PCR assays

\begin{tabular}{lccccccc}
\hline Mosquito species & Total & Human & Dog & Pig & Bovine & Horse & Non-chicken avian \\
\hline Anopheles minimus & 10 & 0 & 2 & 1 & 6 & 0 & 1 \\
Anopheles sinensis & 44 & 0 & 0 & 38 & 4 & 2 & 0 \\
Anopheles maculatus & 4 & 0 & 1 & 0 & 3 & 0 & 0 \\
Anopheles ludlowae & 3 & 0 & 0 & 0 & 2 & 1 & 0 \\
Anopheles tessellatus & 1 & 0 & 0 & 0 & 1 & 0 & 0 \\
Culex tritaeniorhynchus & 27 & 1 & 1 & 21 & 1 & 1 & 0 \\
Culex annulus & 3 & 1 & 1 & 0 & 1 & 0 & 0 \\
Culex fuscocephala & 1 & 0 & 0 & 0 & 1 & 0 & 0 \\
Culex bitaeniorhynchus & 1 & 1 & 0 & 0 & 0 & 0 & 0 \\
Aedes albopictus & 5 & 2 & 0 & 3 & 0 & 0 & 0 \\
Culex quinquefasciatus & 2 & 0 & 0 & 0 & 0 & 2 & 3 \\
Total & 101 & 5 & 5 & 63 & 19 & 6 & 0 \\
\hline
\end{tabular}


implemented at an early stage of the outbreak and not after the epidemic's peak [18]. In this study, Anopheles adults were only collected outside of the houses and surrounding larval habitats. Furthermore, this species fed on the blood of four animals. Therefore, an indoor residual spraying in houses would not be effective; instead, this measure should be applied to animal huts and surrounding larval habitats. However, in this study, only one surrounding larval habitat was suitable for spraying; therefore, the application sites of larval habitats should be carefully evaluated. The second measure was space spraying. Because more Anopheles adults were collected in light traps in the results, a space spray at night would be a good control measure to kill host-searching females. The last was the use of insecticide-treated bed nets, which had been shown to significantly reduce malaria morbidity and mortality in malaria epidemic areas [19-21]. Additionally, a good surveillance and the proper management of malaria imported cases and patient movement is also important to prevent the reintroduction of malaria into Taiwan. Furthermore, routine vector surveillance will provide the valuable information on the trends in vector dynamics and behaviour.

\section{Conclusion}

Anopheles minimus, an opportunist feeder in Taiwan, was not collected inside the houses but were found outside of the houses by backpack aspirators and light traps. Therefore, an outdoor transmission of malaria is likely to occur and, thus, the bed nets, which are favoured for controlling the late biting of An. minimus, should be a very efficient and effective method for those local residents who sleep outdoors. The use of space spray of insecticides for Anopheles at night, as well as residual spray in animal huts and selective larval habitats, are helpful to control adults. Additionally, a good surveillance and the proper management of malaria imported cases and patient movement is also important to prevent the reintroduction of malaria into Taiwan.

\section{Authors' contributions}

MCC carried out the blood-meal identification, collected field data, and helped draft the manuscript, HJT designed the survey, collected field data, performed the statistical analysis, drafted, and polished the manuscript, CFC and YCC provided significant input on data collection in the field and helped draft the manuscript, CRJ participated in the design of the study and critically revised the manuscript. All authors read and approved the final manuscript.

\section{Acknowledgements}

This study was supported by scientific research grants from the Centers for Disease Control, Taiwan in 2005 and 2006 (DOH94-DC-2015 and DOH95-DC-2012).

\section{References}

I. Department of Health: Malaria eradication in Taiwan, 199I. Taipei, Taiwan 1991.

2. Centers for Disease Control-Taiwan: Number of cases and deaths of malaria, 1990-2003. Epi Bull 2003, 19:562. (In Chinese)

3. Centers for Disease Control-Taiwan: Statistics of communicable diseases and surveillance report in Taiwan Area. Taipei, Taiwan 2004.

4. Lien JC: Anopheline mosquitoes and malaria parasites in Taiwan. Kaohsiung J Med Sci I99I, 7(5):207-223.

5. Somboon P, Walton C, Sharpe RG, Higa Y, Tuno N, Tsuda Y, Takagi $M$ : Evidence for a new sibling species of Anopheles minimus from the Ryukyu Archipelago, Japan. J Amer Mosq Control Assoc 200I, 2 I:5-9.

6. Harbach RE: The classification of genus Anopheles (Diptera: culicidae): a working hypothesis of phylogenetic relationships. Bull Entomol Res 2004, 95(6):537-553.

7. Harbach RE, Garros C, Manh ND, Manguin S: Formal taxonomy of species $C$ of the Anopheles minimus sibling species complex (Diptera: Culicidae). Zootaxa 2007, I 654:4I-54.

8. Chen B, Harbach RE, Butlin Rk: Molecular and morphological studies on the Anopheles minimus group of mosquitoes in sourthern China: taxonomic review, distribution and malaria vector status. Med Vet Entomol 2002, I 6:253-265.

9. Somboon P, Thongwat C, Somvang P, Teng HJ, Tsuda Y, Takagi M: The specific status of Anopheles minimus s.l. collected from Taiwan. Southeast Asian J Trop Med Public Health 2005, 36(3):605-608.

10. Harbach RE, Parkin E, Chen B, Butlin RK: Anopheles (Cellia) minimus Theobald (Diptera: Culicidae): Neotype designation, characterization, and systematics. Proc Entomol Soc Washington 2006, 108:198-209.

II. Van Bortel W, Trung HD, Sochantha T, Keokenchanh K, Roelants P, Backeljau T, Coosemans M: Eco-ethological heterogeneity of the members of the Anopheles minimus complex (Diptera: Culicidae) in Southeast Asia and its consequences for vector control. J Med Entomol 2004, 4 I :366-374.

12. Trung HD, Van Bortel W, Sochantha T, Keokenchanh K, Briet OJ, Coosemans M: Behavioural heterogeneity of Anopheles species in ecologically different localities in Southeast Asia: a challenge for vector control. Trop Med Int Health 2005, I 0:25 I-262.

13. Steel RGD, Torrie JH: Principles and procedures of statistics. A biometrical approach 2nd edition. McGraw-Hill Book Company, New York; 1980.

14. Teng HJ, Chen CF, Chao L, Chang LL: Mosquito vector surveillance in Taiwan. In Proceeding of the 19th FAOPMA Convention and International Exhibition on Pesticides, Material and Equipment: 14-16 November 2007; Taipei, Taiean Chinese Pest Control Association; 2007:55-64.

15. Trung HD, Bortel WV, Sochantha T, Keokenchanh K, Quang NT, Cong LD, Coosemans M: Malaria transmission and major malaria vectors in different geographical areas of Southeast Asia. Trop Med Int Health 2004, 9(2):230-237.

16. Morishita K, Katagai T: Studies on blood feeding of Formosan anophelines. (First report) Investigation of blood in the stomach by precipitin tests. J Med Assoc Formosa 1933, 32:593.

17. World Health Organization: Malaria vector control and personal protection: report of a WHO study group WHO Technical Report Series; no. 936; 2006.

18. Protopopoff N, Van Herp M, Maes P, Reid T, Baza D, D'Alessandro $U$, Van Bortel W, Coosemans M: Vector control in a malaria epidemic occurring within a complex emergency situation in Burundi: a case study. Malar J 2007, 6:93.

19. Nevill CG, Some ES, Mung'ala VO, Mutemi W, New L, Marsh K, Lengeler C, Snow RW: Insecticide-treated bednets reduce mortality and severe morbidity from malaria among children on the Kenyan coast. Trop Med Int Health 1996, I:I39-146.

20. Fegan GW, Noor AM, Akhwale WS, Cousens S, Snow RW: Effect of expanded insecticide-treated bednet coverage on child survival in rural Kenya: a longitudinal study. Lancet 2007, 370:1035-1039.

21. D'Alessandro $U$, Olaleye BO, McGuire $W$, Langerock P, Bennett $S$, Aikins MK, Thomson MC, Cham MK, Cham BA, Greenwood BM: Mortality and morbidity from malaria in Gambian children after introduction of an impregnated bednet programme. Lancet 1995, 345:479-483. 
22. Ngo KA, Kramer LD: Identification of mosquito bloodmeals using polymerase chain reaction (PCR) with order-specific primers. J Med Entomol 2003, 40:2 I5-222.

23. Lahiff S, Glennon M, O'Brien L, Lyng J, Smith T, Maher M, Shilton N: Species-specific PCR for the identification of ovine, porcine and chicken species in meat and bone meal (MBM). Mol Cell Probes 200I, I 5(I):27-35.

24. Parodi B, Aresu O, Bini D, Lorenzini R, Schena F, Visconti P, Cesaro $M$, Ferrere MD, Andreotti $\bigvee$, Ruzzon T: Species identification and confirmation of human and animal cell lines: a PCR-based method. BioTechniques 2002, 32:432-440.

Publish with Bio Med Central and every scientist can read your work free of charge

"BioMed Central will be the most significant development for disseminating the results of biomedical research in our lifetime. "

Sir Paul Nurse, Cancer Research UK

Your research papers will be:

- available free of charge to the entire biomedical community

- peer reviewed and published immediately upon acceptance

- cited in PubMed and archived on PubMed Central

- yours - you keep the copyright

Submit your manuscript here:

http://www.biomedcentral.com/info/publishing_adv.asp 